\title{
AN ANALYTICAL STUDY FOR SOME ECONOMIC IMPACT OF THE GLOBAL FINANCIAL CRISIS ON THE PRODUCTION OF FABA BEAN CROP IN GHARBIA GOVERNORATE
}

Easa, E. E.

Agricultural Economic Research Institute, Agric. Res. Center

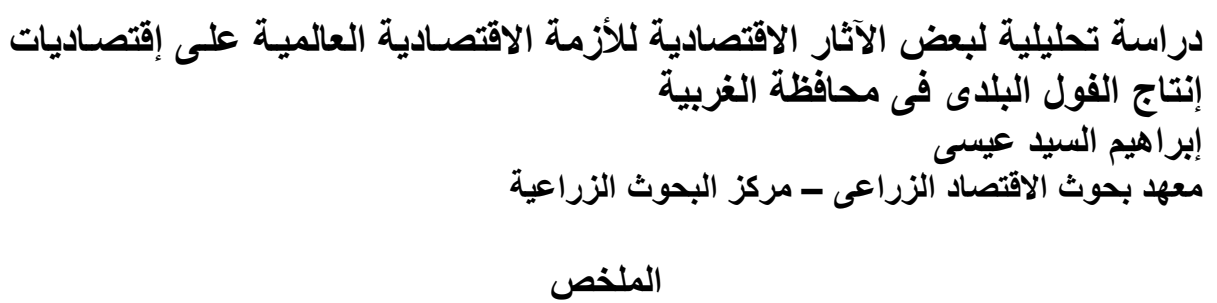

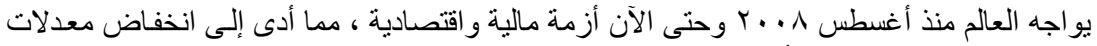

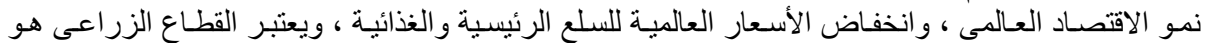

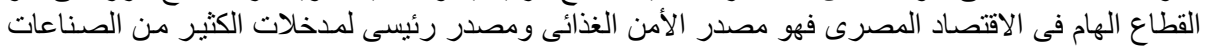

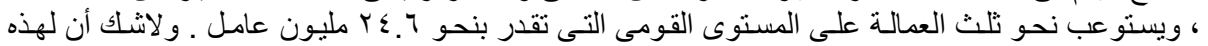

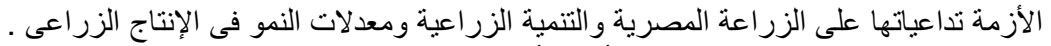

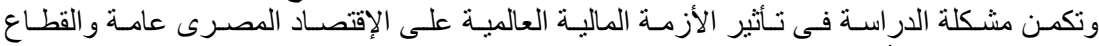

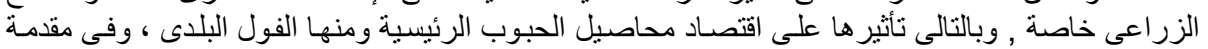

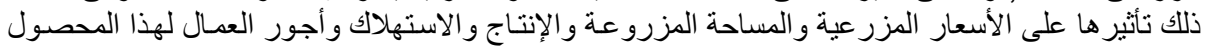

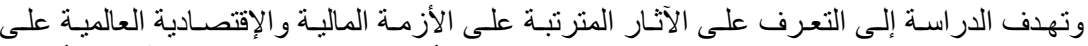

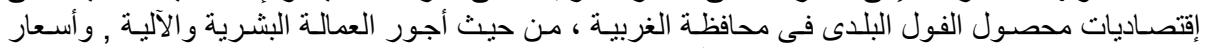

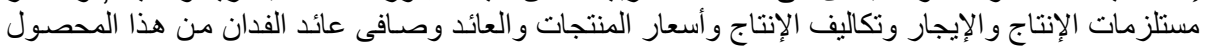

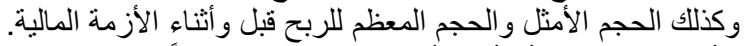

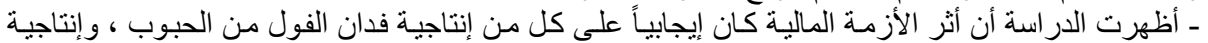

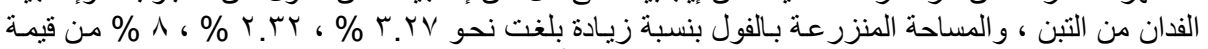

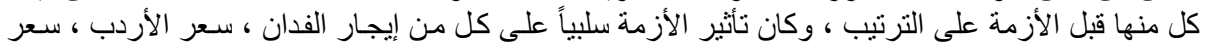

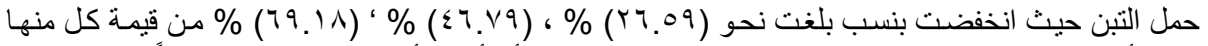

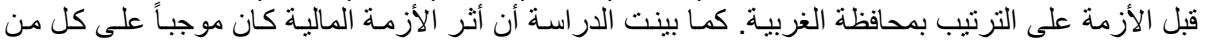

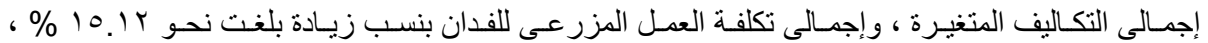

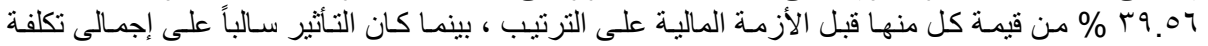

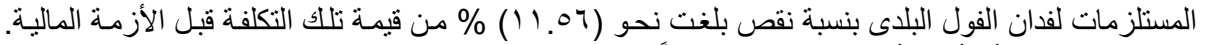

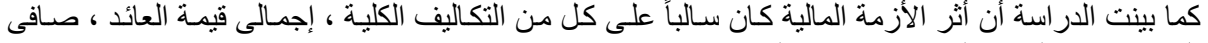

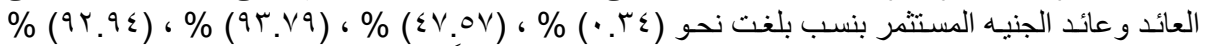

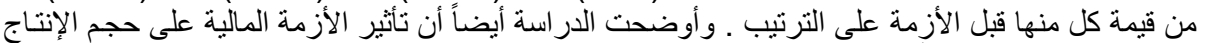

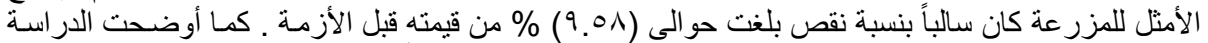

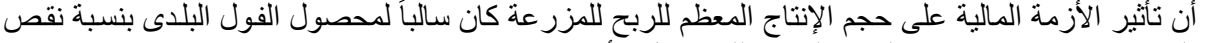

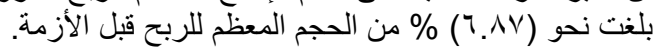


Easa, E. E.

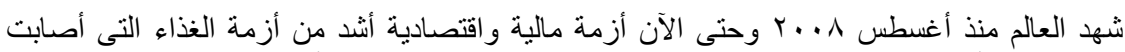

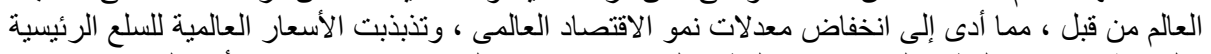

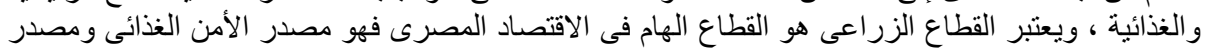

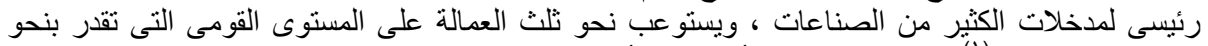

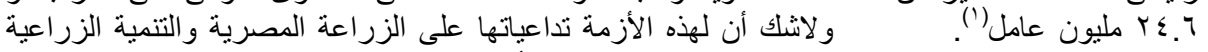

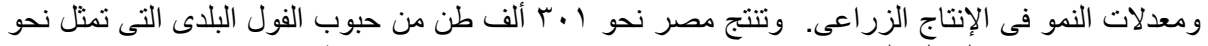

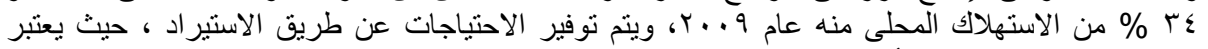

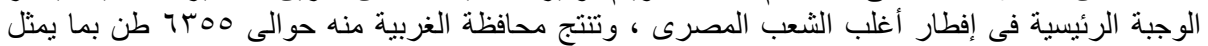

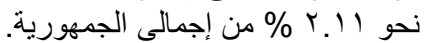

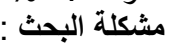

تعتبر محاصيل الحبوب الرئيسية والبقوليات من الأهمية بمكان اقتصادياً وزراعياً وغذائياً فى الاقتصاد

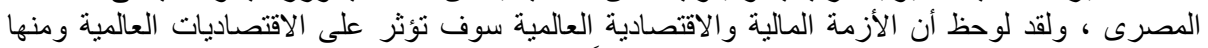

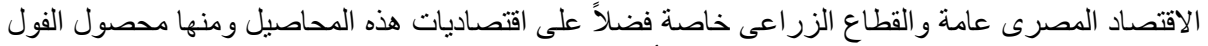

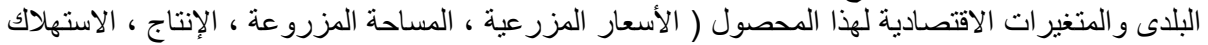

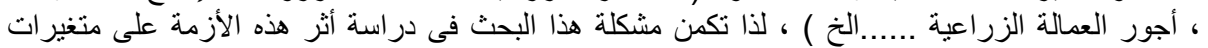

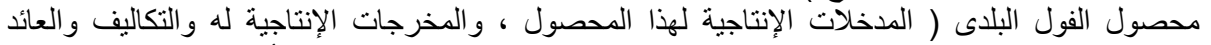
وصافى العائد ، حيث تعتمد مصر فى نسبة كبيرة من الاستهلاك على الاستير اد من الأسواق العالمية العية ) .

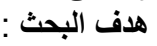

يهذف البحث إلى تتبع وتحليل بعض الآثار الاقتصادية للأزمة المالية والاقتصادية العالمية على فلى

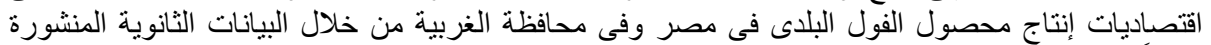
فضلاً عن بيانات قطاع مستعرض ( عينة من المزارعين فى محافظة الغربية ).

\section{مصادر البيانات والأسلوب البحثى}

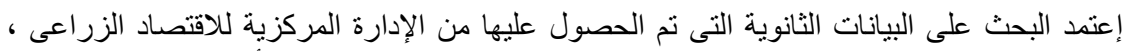

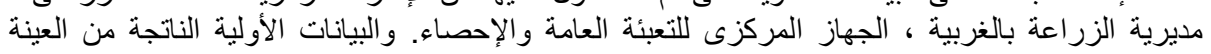

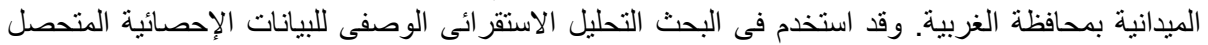

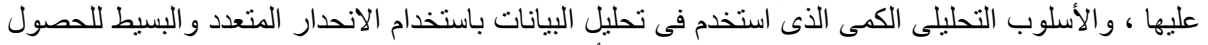
على دوال الإنتاج ، ودو ال التكاليف ، وحساب الحجم الأمثل و المعظم للربح لمحصول الفئل الفول البلاي فى محافظة

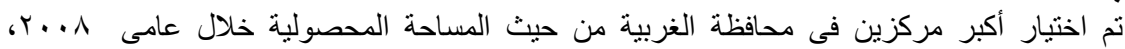

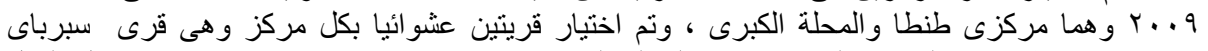

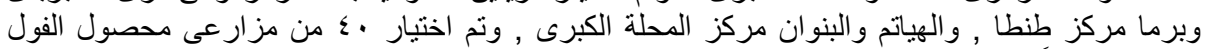

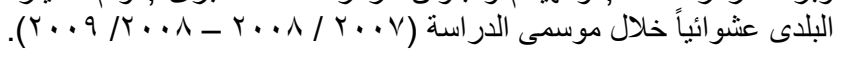

\section{النتائج ومناقشتها}

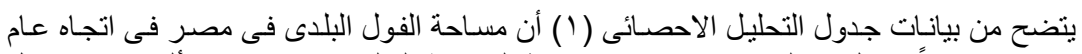

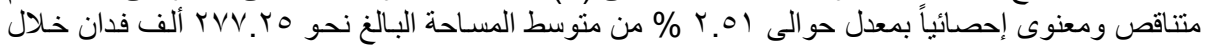

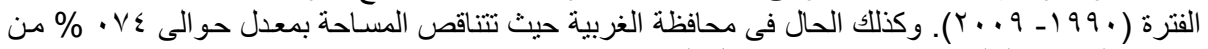

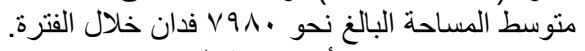

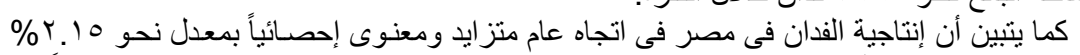

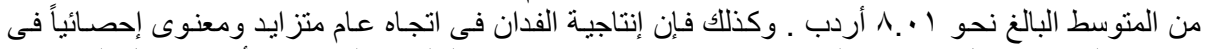

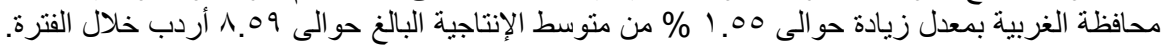

$$
\text { (') الجهاز المركزى للتعبئة العامة و الإحصاء - بحث القوى العاملة م . . † . }
$$




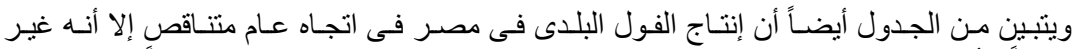

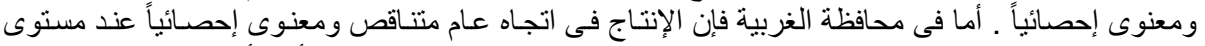

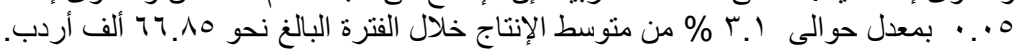

جدول رقم ( ) : معـالم معـادلات الاتجـاه الزمنى العـام لتطور كل من المسـاحة والإنتاجية الفدانية والإنتاج

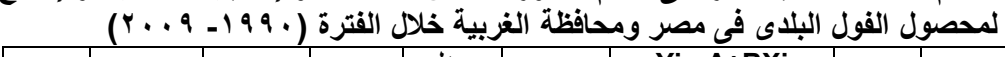

\begin{tabular}{|c|c|c|c|c|c|c|c|c|c|c|}
\hline \multirow[b]{2}{*}{ المعنوية } & \multirow{2}{*}{ للنموذج } & \multirow{2}{*}{$\begin{array}{c}\text { T } \\
\text { المحسوبة }\end{array}$} & \multirow{2}{*}{$\mathbf{R}^{2}$} & \multirow{2}{*}{ 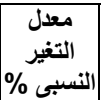 } & \multirow[b]{2}{*}{ المتوسط } & \multicolumn{2}{|c|}{$Y i=A+B X i$} & \multirow[b]{2}{*}{ رقادثة } & \multirow[b]{2}{*}{ المتغير التابع [Y] } & \multirow[b]{2}{*}{ البيان } \\
\hline & & & & & & A & B & & & \\
\hline ** & $10.1 \mathrm{rV}$ & r.A9) - & $\cdot \varepsilon r V$ & $r .01$ & TVV.YO & ro. TוT & $7.909-$ & 1 & مساحة الفول & \\
\hline ** & $10.01 \varepsilon$ & $r .949$ & $\cdot . \leqslant r \mu$ & 5.10 & 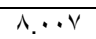 & 7.191 & $\cdot . I V Y$ & r & إنتاجية الفدان & \\
\hline-- & $\cdot .7 r$ & - & $\because \cdot Y I$ & $\because V \leqslant$ & YY.T.A & rTVA. YE & II.TYA - & $r$ & إجمالى الإنتاج & \\
\hline$\star *$ & Tr.rTr & ะ.VYq - & $.00 \leqslant$ & $\varepsilon . \vee$. & $\vee .91$ & $11.91 \mathrm{~V}$ &. rvo & $\varepsilon$ & مساحة الفول & 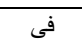 \\
\hline ** & $1 \% . \wedge 7$. & T.VTT & $\because \leqslant T 0$ & 1.00 & 1.09 & $8.19 r$ &. $.1 \pi r$ & 0 & إنتاجية الفدان & محافظة \\
\hline * & 7.171 & T. $\leqslant \wedge \leqslant-$ &.$Y 00$ & $r . v$ & 77.10 & Aג.rד & T.P $\{9-$ & 7 & إجمالّى الإنتاج & الغربية \\
\hline
\end{tabular}

ـ أثر الأزمة المالية العالمية على بعض المتغيرات الخاصة بإنتاج محصول الفول البلدى فى محافظة الغربية:

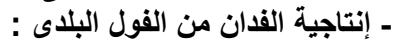

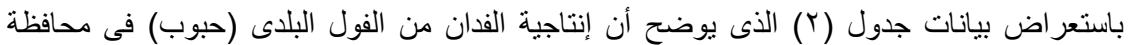

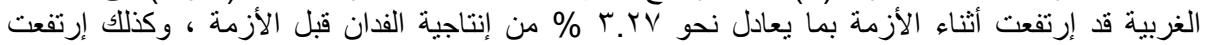

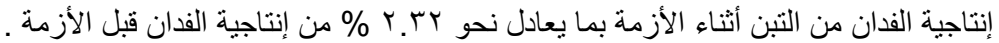

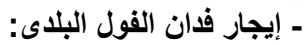

يوضح جدول (Y) أن أثر الأزمة المالية العالمية على إيجار الفدان من الأرض كأن الفان سلبياً , حيث

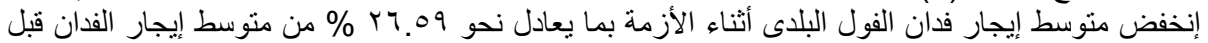

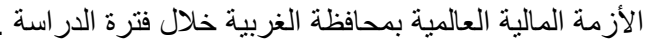

جدول (Y): أثر الأزمة المالية العالمية على متوسط بنود الإنتاجية الفدانية والإيجار وسعر المنتج الرئيسي الفيس

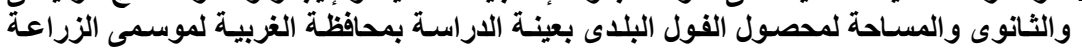

\begin{tabular}{|c|c|c|c|}
\hline \multicolumn{4}{|c|}{ 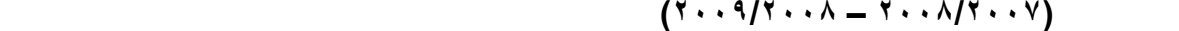 } \\
\hline معدل التغير (') - مع & 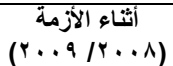 & 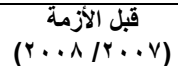 & 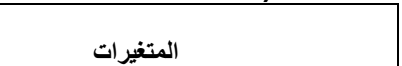 \\
\hline r.Tr & 1. vo & $1 \cdot . \varepsilon 1$ & إنتاجية فدان الفول من الحبوب (أردب/ فدان) \\
\hline ritr & $0 . v \pi$ & 0.7 & إنتاجية الفدان من تبن الفول (حمل/ فدان) \\
\hline$($ (Y.09) & $1 \wedge .7 . .$. & $r \leqslant 7 . r_{0}$ & إيجار فدان الفول (جنيد/ فدان) \\
\hline$(\leqslant 7, \vee 9)$ & $r v \cdot$. & $790 . r \varepsilon$ & سععر الأردب من الفول (جنيه/ أردب) \\
\hline$(79.11)$ & $\varepsilon \Lambda_{.}$. & $100 . V \varepsilon$ & لسعر حمل التبن من الفول (جنيه/ حمل) \\
\hline
\end{tabular}

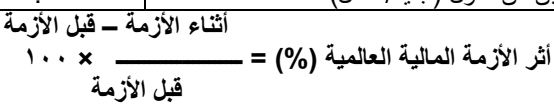

المصدر : جمعت وحسبت من بيانات الاستبيان الميدانى الخاصة بالعينة.

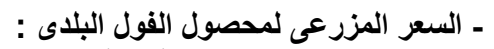

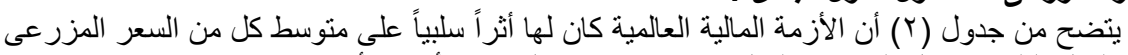

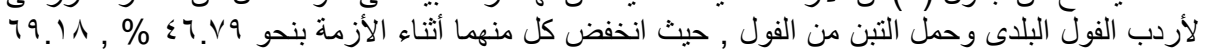

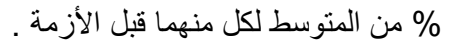

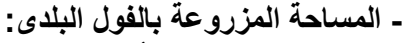

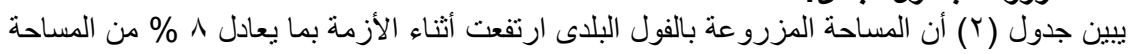

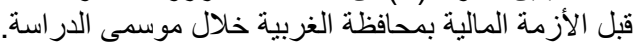


Easa, E. E.

- هيكل تكاليف الإنتاج (العمل المزرعى ومستلزمات الإنتاج) لفان الفول البلدى فى محافظة الغربية:

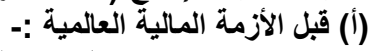

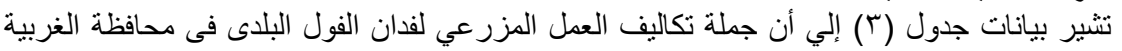

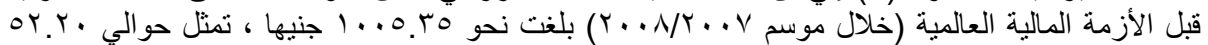

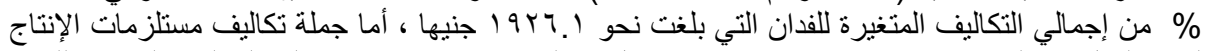

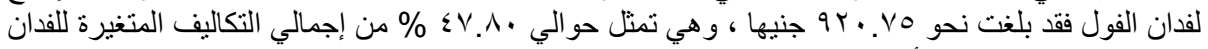

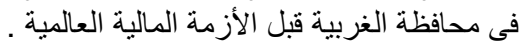

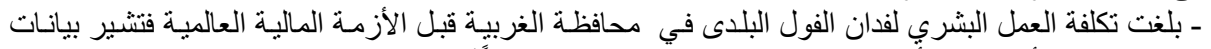

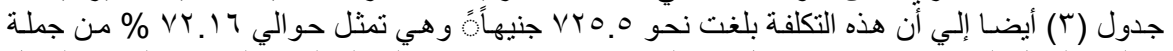

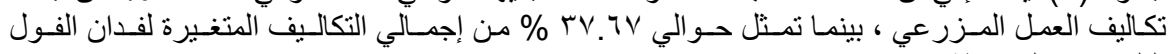

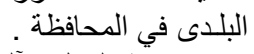

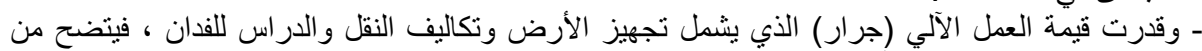

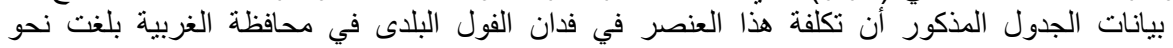

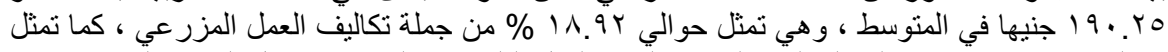

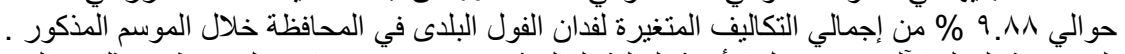

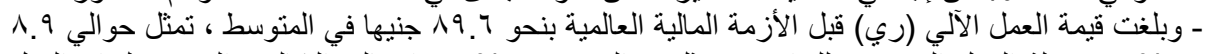

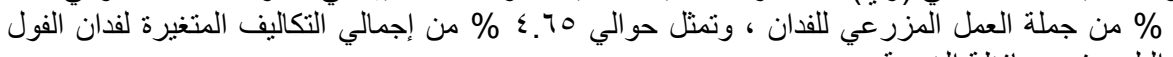
البلاى فى محافظة الغربية .

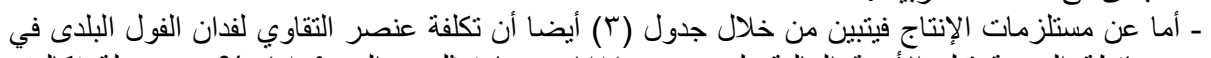

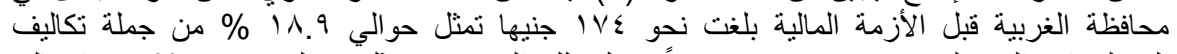

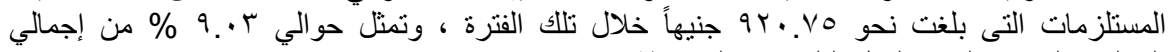
التكاليف المتغيرة لفدان الفول البلادى في الدحافظة.

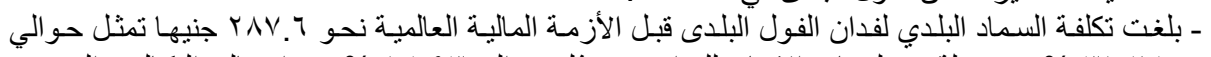

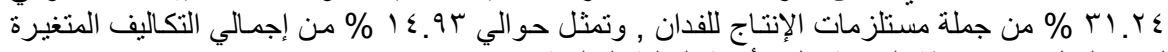

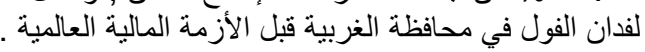

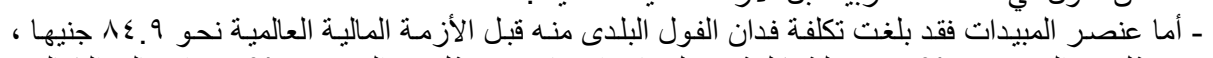

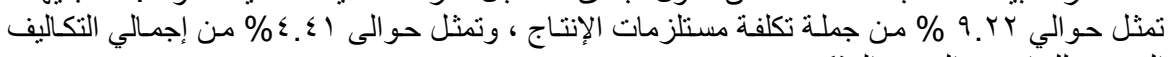
المالغنيرة للفذان في الموسم المذكور.

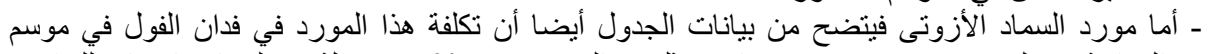

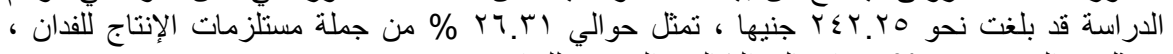

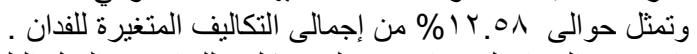

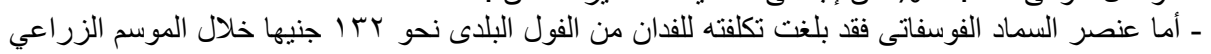

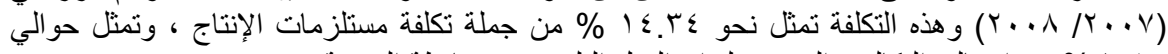

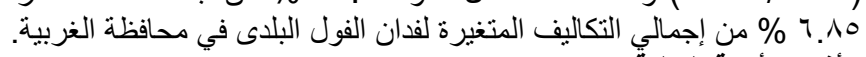
(ب) أثناء الأزمة المالية

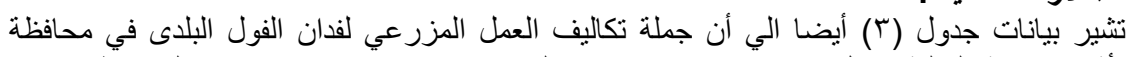

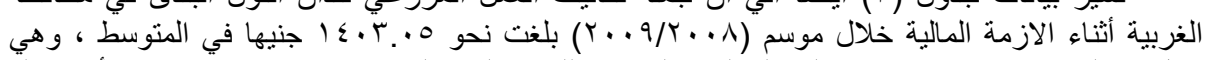

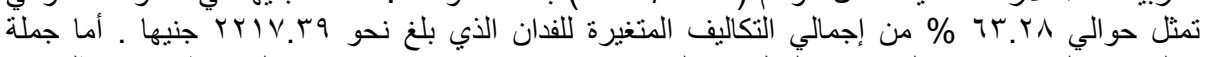

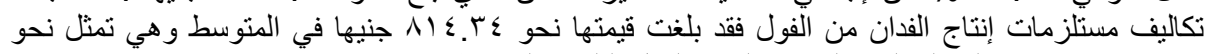

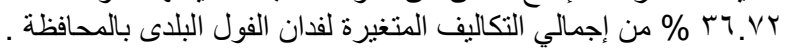

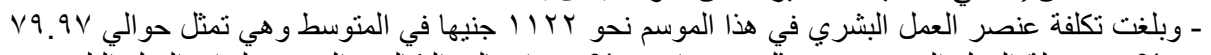

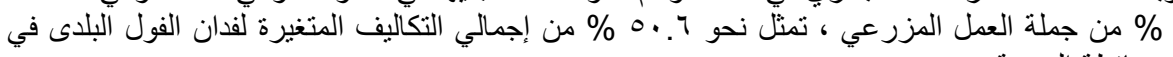
م افظظة الغربية.

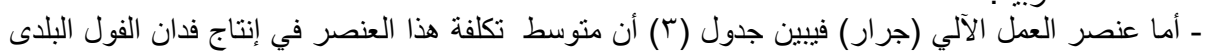

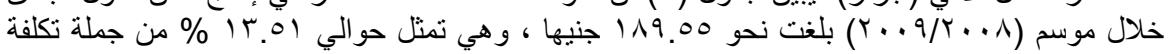

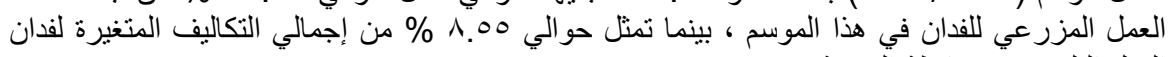
الفول البلاى في محافظة التغربية. 
جدول (َ) :متوسط قيم المتغيرات الإنتاجية والتكاليف المتغيرة لفدان الفول البلدى قبل وأثناء الأزمـة المالية

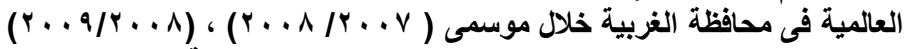
القيمة بالجنيه

\begin{tabular}{|c|c|c|c|}
\hline معدل التغير \% & 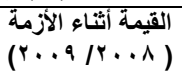 & 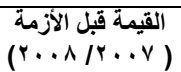 & المتغيرات \\
\hline $0 \leqslant .70$ & IIr... & VYO. & لة العمل البشرى \\
\hline$(\cdot r v)$ & 119.00 & $19 . .10$ & قيمة العمل الآلى (جرار) \\
\hline t. & 91.0 & 19.7 & ثيمة العمل الآلى (رى) \\
\hline$r 9.07$ & $1 \varepsilon \cdot r .0$ & $1 \ldots 0.10$ & إجمالى تكلفة العمل المزرعى \\
\hline$\left(r \cdot . I^{\prime}\right)$ & $1 Y 1.7$ & IV & ثيمة التقاوى ت \\
\hline $11 . \leqslant V^{\prime}$ & r.t. & $Y \wedge \vee . T$ & قيمة السماد البلدى \\
\hline$\varepsilon 0.1 \mathrm{~V}$ & OTHE & $\wedge \leqslant .9$ & قيمة المبيدات \\
\hline$(Y 7.00)$ & IVT.人T & $r \leq r . r_{0}$ & قيمة السماد الأزوتى \\
\hline$(\leqslant 0 . \leqslant 7)$ & $V Y_{.} .$. & ITr. & ثيمة السماد الفوسفاتى \\
\hline$(11.07)$ & $\lambda I \leqslant . \Gamma \leq$ & $9 Y \cdot .10$ & إجمالى تكاليف مستلزمات الإنتاج \\
\hline 10.11 & rYIV.rq & $19 \times 7.1$. & إجمالى التكاليف المتغيرة \\
\hline
\end{tabular}

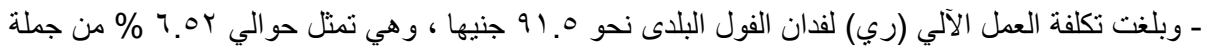

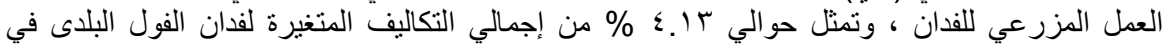

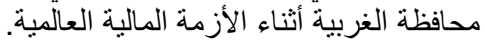

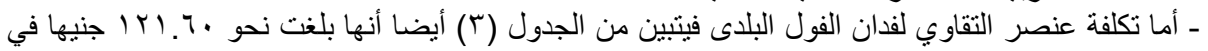

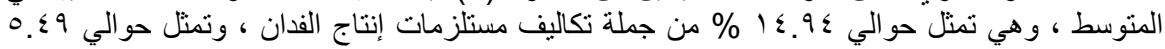

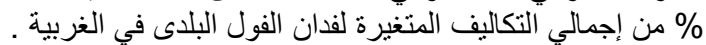

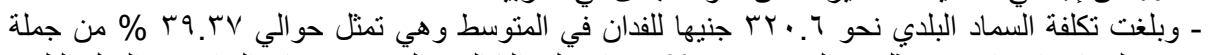

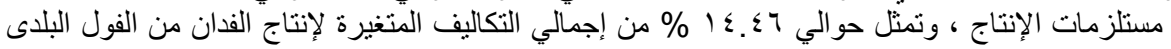

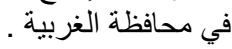

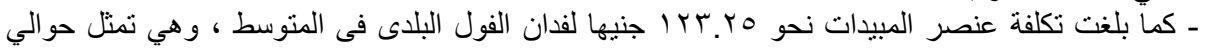

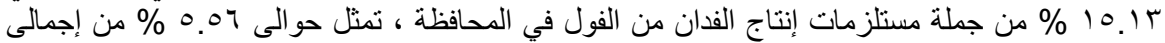

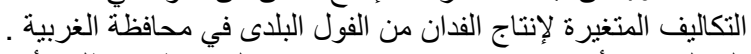

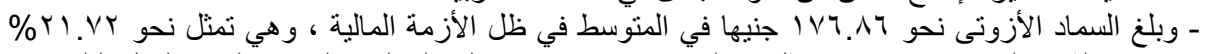

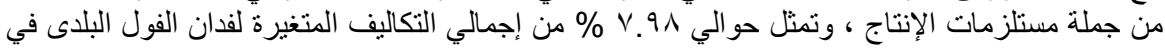

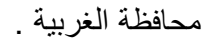

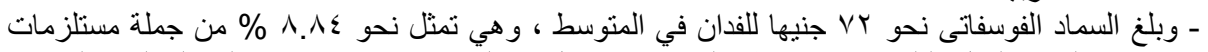

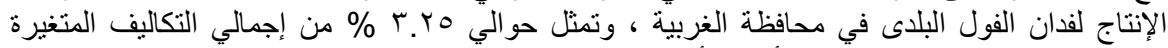

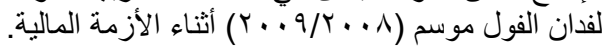

(ج) تأثير الأزمة المالية على هيكل كل من العمل المزرعى ومستلزمات الإتتاج للفدان من محصول الفول

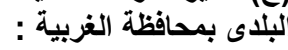

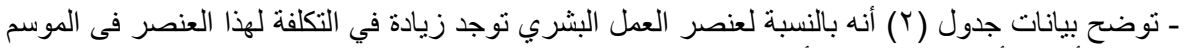

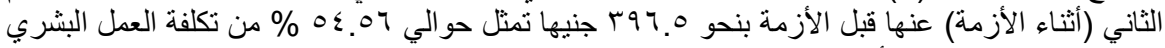

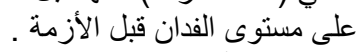

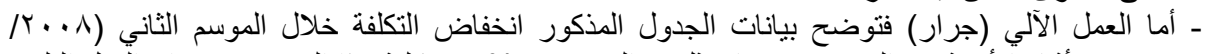

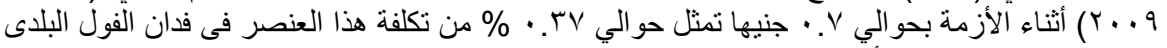

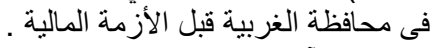

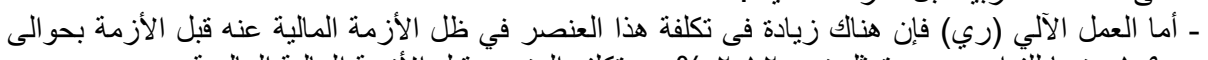

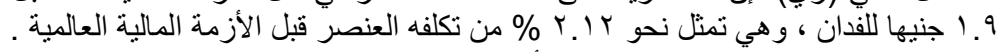

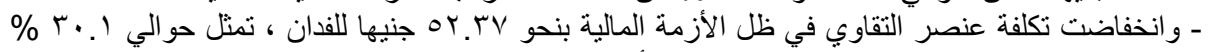
من تكلفة هذا العنصر فى محافظة الغربية قبل الأزمة المالية العالمية . 


\section{Easa, E. E.}

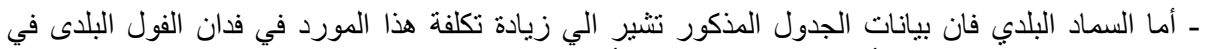

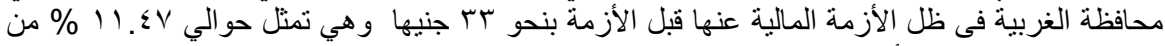

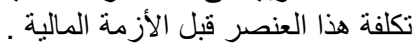

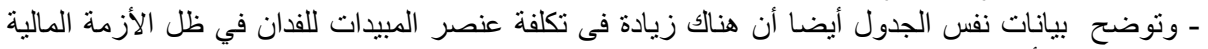

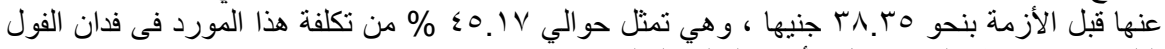

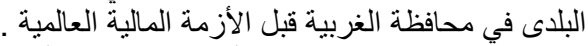

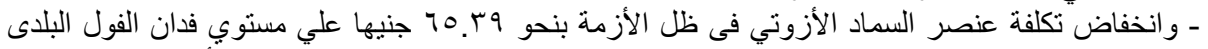

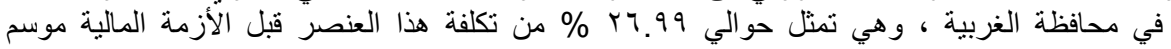

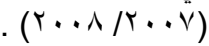

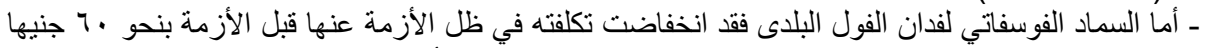

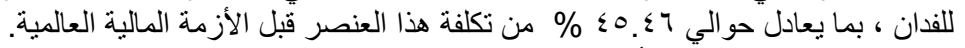

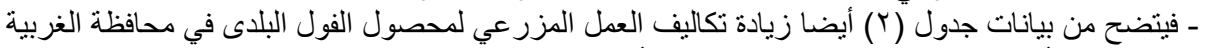

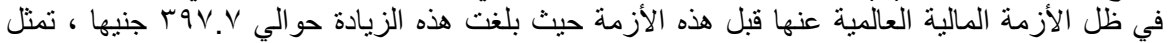

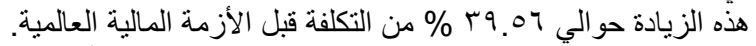

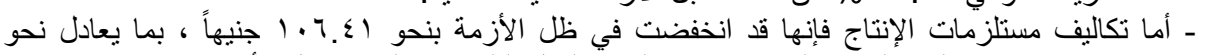

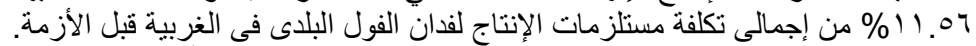

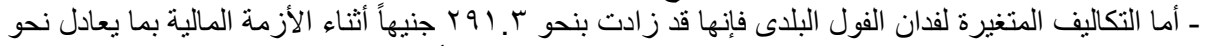

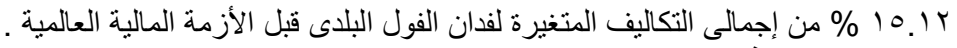

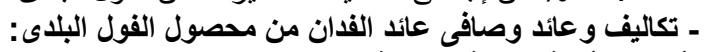

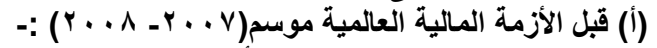

تثنير بيانات جدول (ع) إلى أن جملة التكاليف المتغيرة لفدان الفول البلاى فى محافظة الغربية خلال

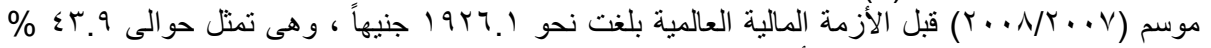

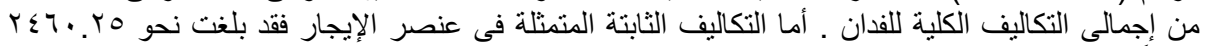

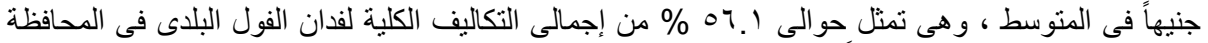

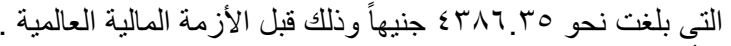

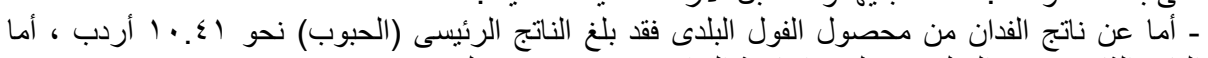

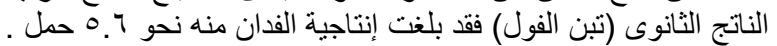

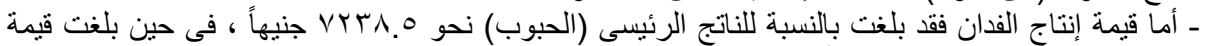

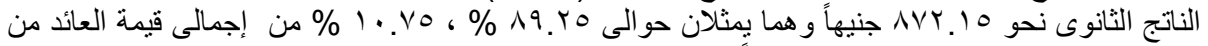

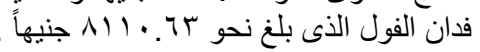
- وقد بلغ صافى العائد من فدان الفول البلان البلدى فى محافظة الغربية قبل الأزمة المالية العالمية موسم

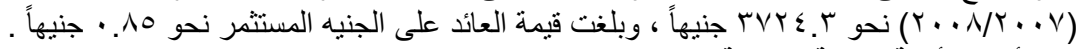

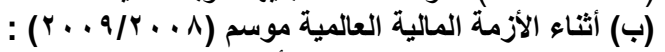

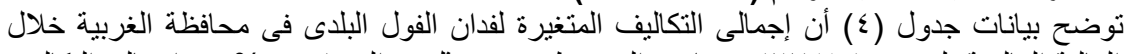

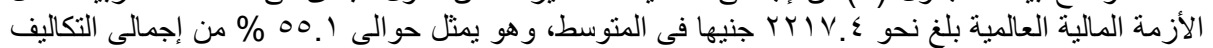

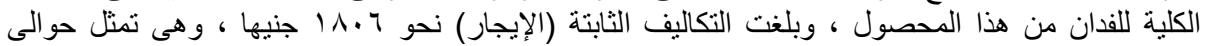

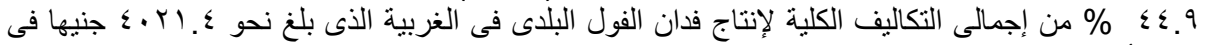

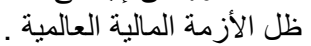

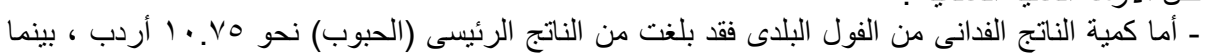

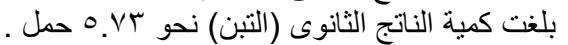

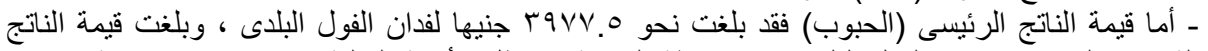

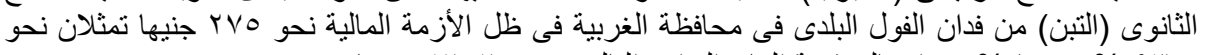

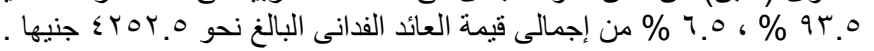

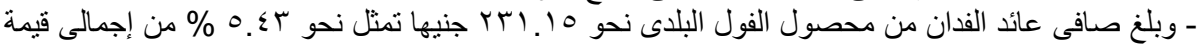
العائد الفدانى الدذكور ـ كما بلغ العائد على الجنيه المستئمر فى إنتاج فدان الفول البلائ في هذا الكوسم نحو 


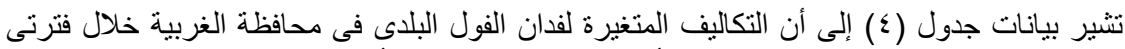

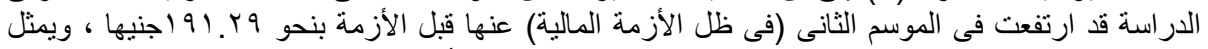

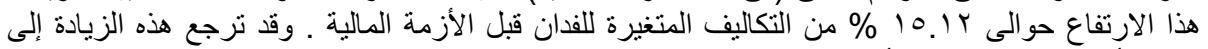

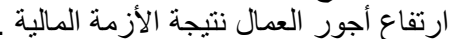

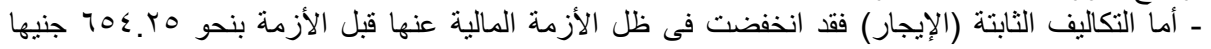

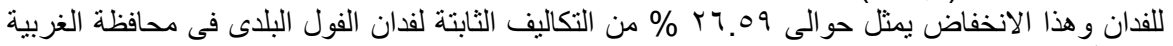
قبل الأزمة المالية

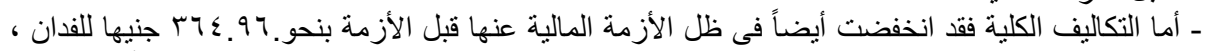

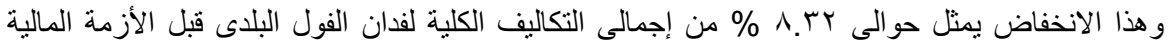

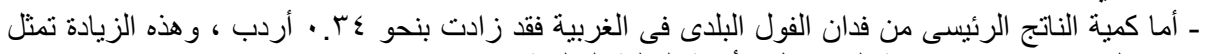

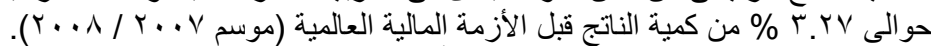

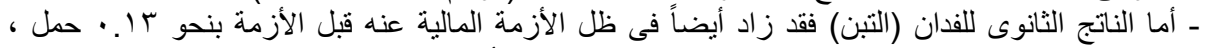

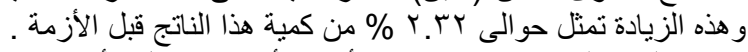

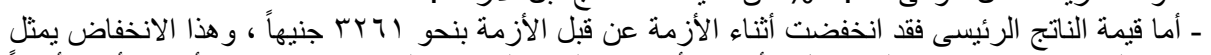

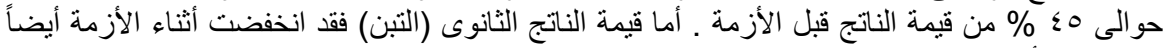

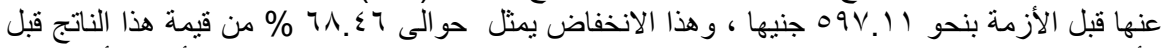

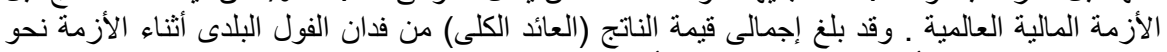


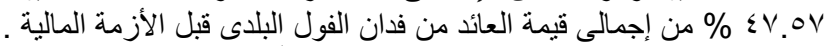

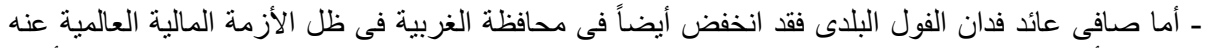

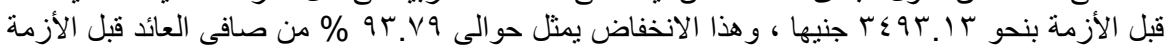

- وبالنسبة للعائد على الجنيه المستثمر فى إنتاج فدان الفول البلدى فى محافظة الغربية فقد أشارت بيانات جدول

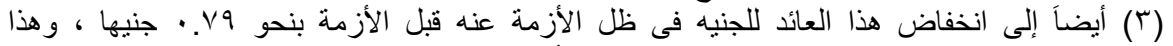

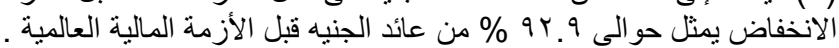

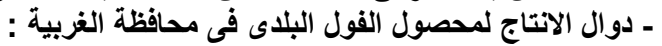
اـ دالة إنتاج الفول البلاى قبل الأزمة المالية العالية العالمية :

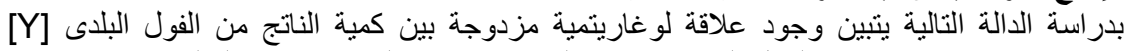

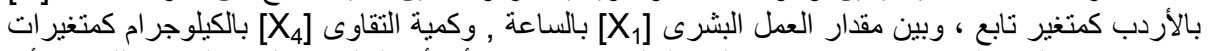

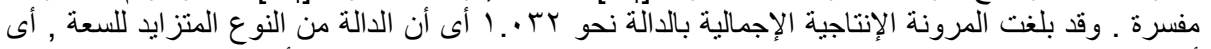

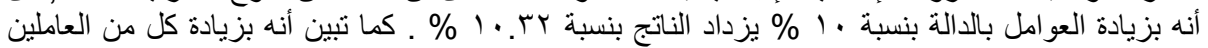

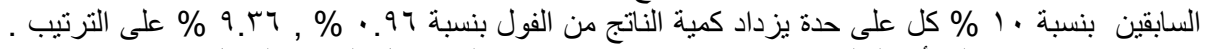

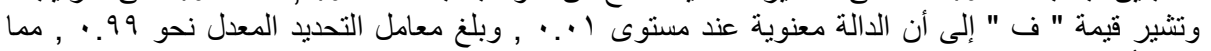

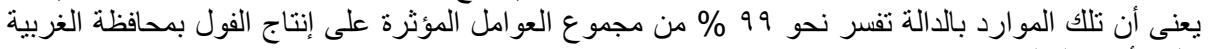

$$
L Y=-0.533+0.096 L_{1}+0.936 L_{4}
$$
قبل الأزمة المالية .

$$
(0.272) \quad(2.616)^{\star *}
$$

$$
\text { المرونة =r r r. }
$$

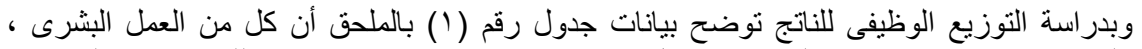

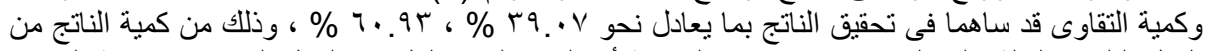

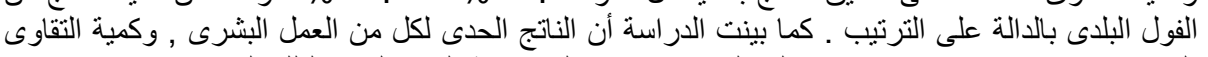

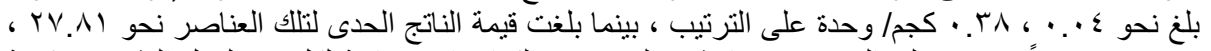

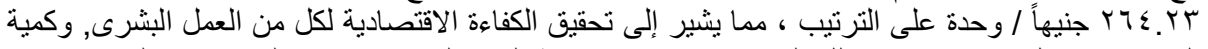

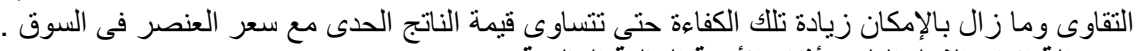

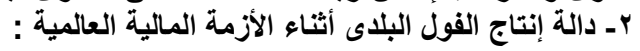

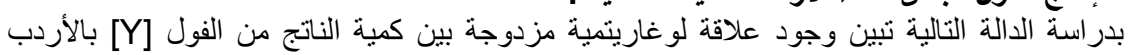

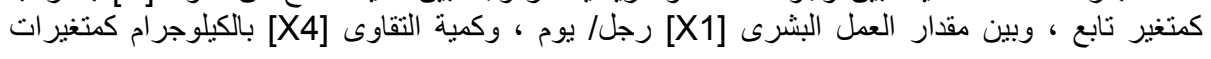




\section{Easa, E. E.}

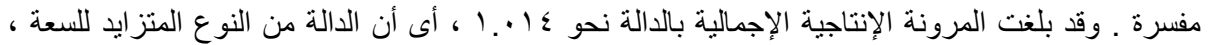

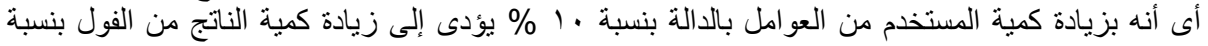

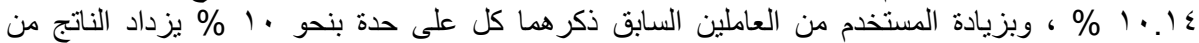

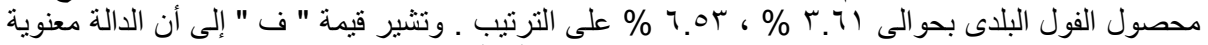

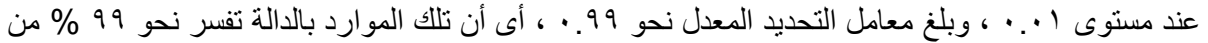
مجموع العوامل المؤثرة على إنتاج الفولَ البلاى بمحافظة الغربية أثناء الأزمة المالية. LY = - 0.525 + 0.361 LX1 + 0.653 LX4

$$
(3.178)^{\star *} \quad(5.673)^{* *}
$$

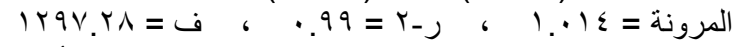

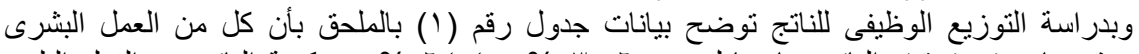

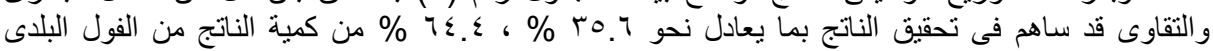

\begin{tabular}{|c|c|c|c|}
\hline \multicolumn{4}{|c|}{ الأزمة المالية العالمية } \\
\hline معدل التغير \% & 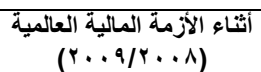 & 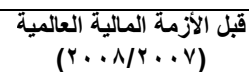 & المتغير \\
\hline $10.1 Y$ & rYIV.rq & 1947.1 & |التكاليف المتغيرة \\
\hline$(47.09)$ & $11.7 .$. & $r \leqslant 7 . r_{0}$ & |التكاليف الثابتة \\
\hline (A.ru) & E.ri,rq & 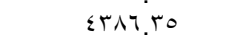 & |التكاليف الكلية \\
\hline tikd & 1. vo & 1.21 & كمية الناتج الزئيسى بالأردب \\
\hline r.rt & $0 . v r$ & 0.7 & كمية الناتج الثانوى بالحمل \\
\hline$(\leqslant 0.0)$ & rav. 0 & VYrA. \&A & تيمة الناتج الرئبسى \\
\hline$(7 \Lambda . \leqslant 7)$ & rvo.e & AVY.10 & لقيمة الناتج الثنانوى \\
\hline$\left(\varepsilon v \circ v^{\prime}\right)$ & sror.os & זי. & إنجمالى قيمة الناتج \\
\hline$(9 r . \vee 9)$ & rTI.10 & TYY Y YA & صنافى العاند الفدانىى \\
\hline$(94.9 \varepsilon)$ & $\because 9$ & $\therefore .10$ & |العائد على الجنيه المستثمر \\
\hline
\end{tabular}

جدول ( ) : التكاليف وكمية وقيمة الناتج وصافى العائد لفدان الفول البلاى فى محافظة الغربية قبل وبعد

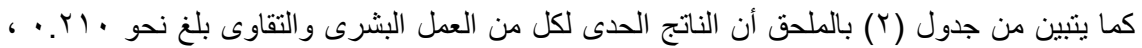

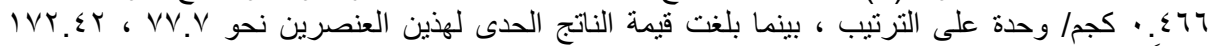

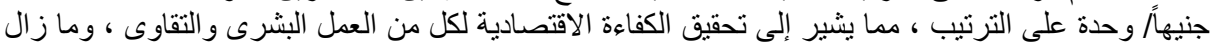

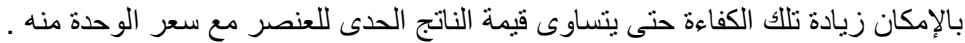

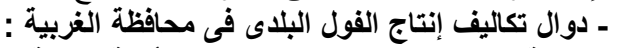

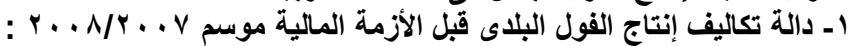

$$
\begin{array}{ccc}
\mathrm{T} c \mathrm{i}= & 54.876+499.606 \mathrm{Xi}-25.437 \mathrm{Xi}^{2}+1.139 \mathrm{Xi}^{3} \\
(4.184)^{* *} & (-1.804) \quad(2.549)^{*}
\end{array}
$$

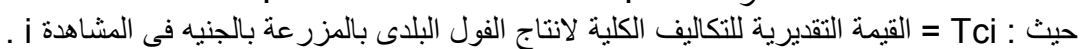

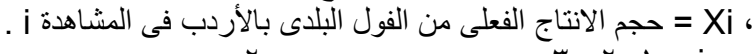

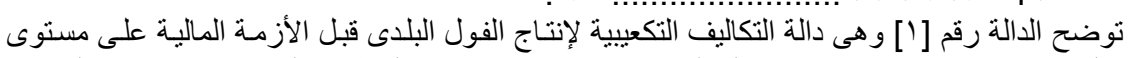

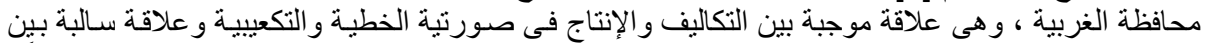

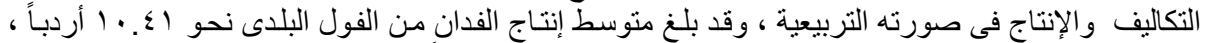

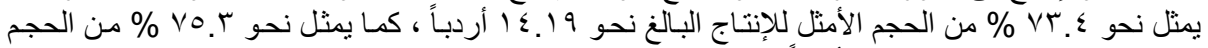

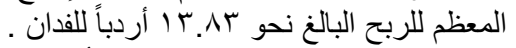

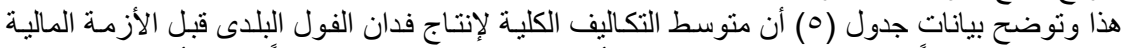

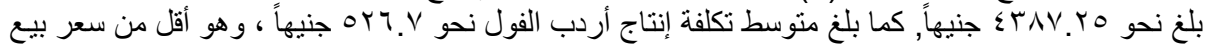




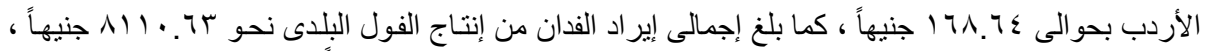

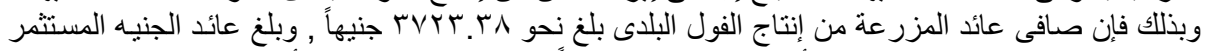

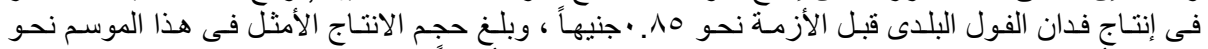

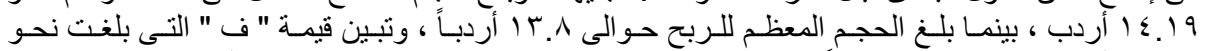

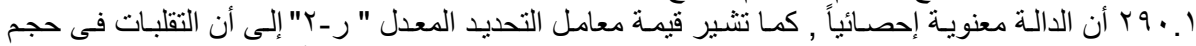

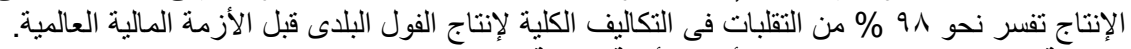

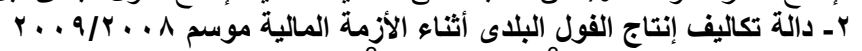
$\mathrm{Tci}=57.469+369.737 \mathrm{Xi}-1.491 \mathrm{Xi}^{2}+0.089 \mathrm{Xi}^{3}$ $\begin{array}{lll}(8.597)^{* *} \quad(-0.267) \quad(0.452) & 0\end{array}$

$$
\text { I7Tr.V V V = ف } \quad \because 99=r
$$

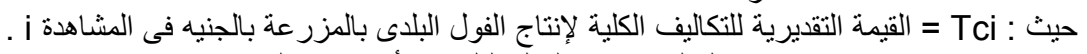

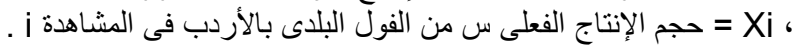
r.

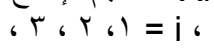

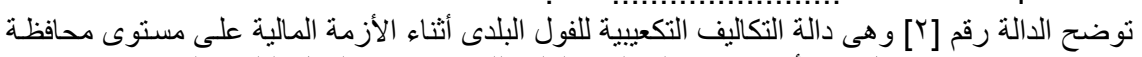

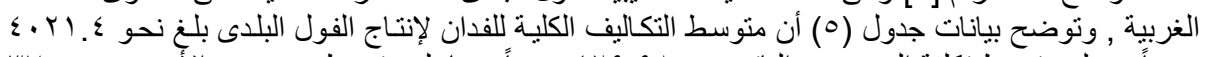

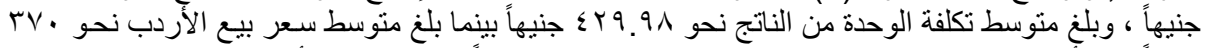

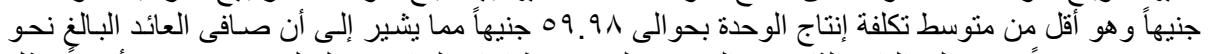

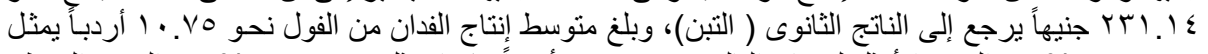

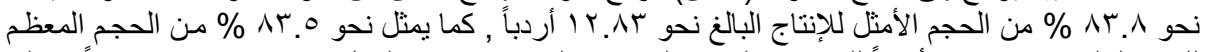

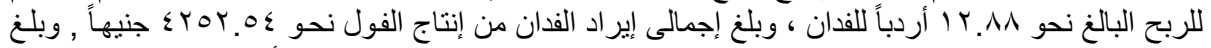

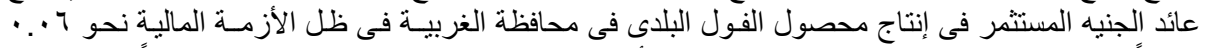

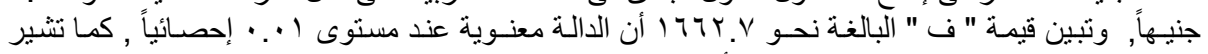

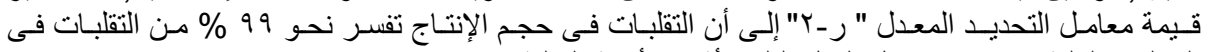
التكاليف الكلية لإنتاج محصول الفول البلاى أثناء الأزمة المالية .

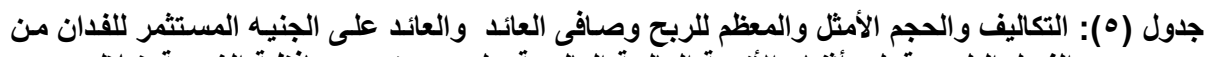

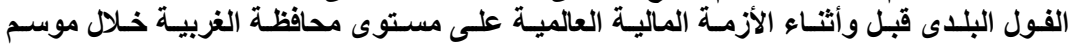

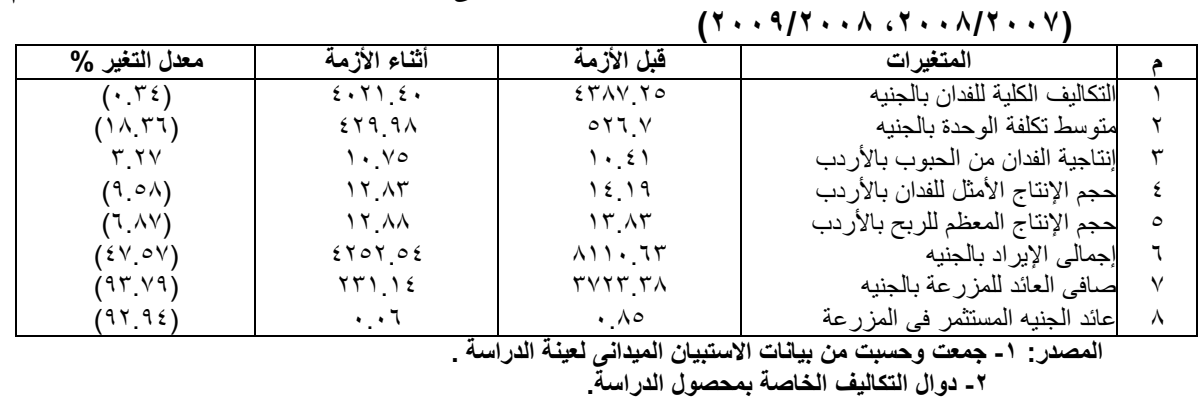

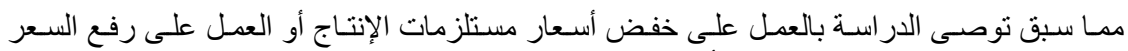

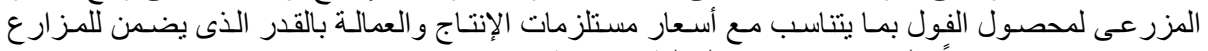
صافى عائد يكون حافزاً على الاستمرار فى العطلية الإنتاجية.

المراجع 
Easa, E. E.

1ـ أحمد أحمد جويلي (دكتور) - الأزمة المالية والاقتصادية العالمية وتداعراتها على الزر اعة المصرية -

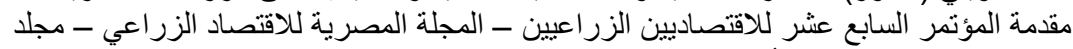

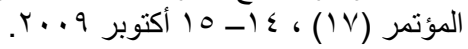

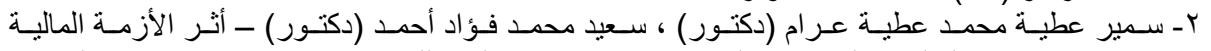

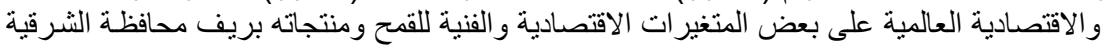

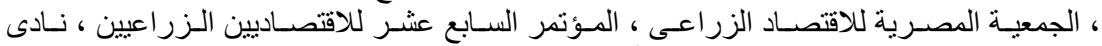

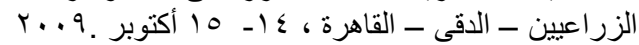

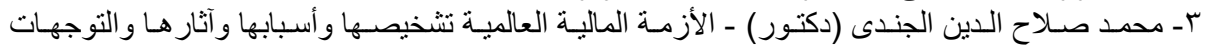

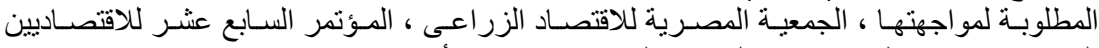

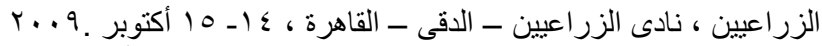

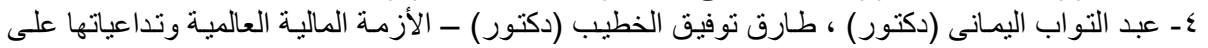

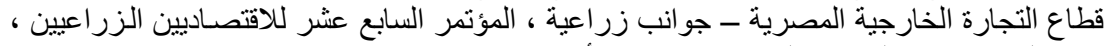

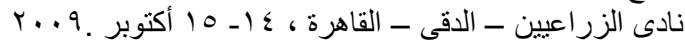

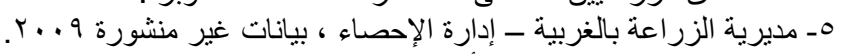

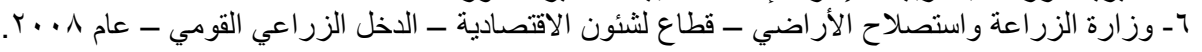

الملاحق

جدول ملحق ( ) : مساحة وإنتاجية وإنتاج محصول الفول البلاى فى مصر ومحافظة الغربية خلال الفترة

\begin{tabular}{|c|c|c|c|c|c|c|}
\hline \multicolumn{3}{|c|}{ فحى محافظة الغربية } & \multicolumn{3}{|c|}{ فى مصر } & \multirow[t]{2}{*}{ البيان } \\
\hline ألف ألتردب & أردب/ الإنتاجية & بالألف فدانة & ألف الأردباج & أردب/فإنانة & بالألف فـاحة & \\
\hline$\vee 9.8$ & $7 . \leqslant 1$ & IY.r & $r \leq 1 \wedge$ & $V .91$ & $r \cdot r$ & 199. \\
\hline or. & $\varepsilon . \wedge r$ & 11. & lNrq & T. Yo & rar & 1991 \\
\hline oร.. & ^.11 & 7.7. & $19 . r$ & 7.07 & rq. & 1994 \\
\hline $9 . .1$ & $\vee .9 V$ & ii.r & $1 v 00$ & 7.7. & צדז & 1994 \\
\hline TV.T & א.ד & $\vee . \wedge$ & $r \cdot \leqslant \Lambda$ & 0.99 & $r \leq r$ & $199 \varepsilon$ \\
\hline VT.o & 9.19 & $\Lambda_{.}$. & ror & 1.09 & r9o & 1990 \\
\hline 1. & A.vi & 11.9 & rAOE & A.TV & rrq & 1997 \\
\hline Ir $9 . V$ & 9.91 & Ir. & r.VT & 1.70 & roo & $199 \mathrm{~V}$ \\
\hline VT.q & v.rq & $1 \cdot$. & Trvo & A.VV & rso & 1991 \\
\hline 79.4 & $1.0 \leqslant$ & ^.i. & 1911 & $7 . M Y$ & M19 & 1999 \\
\hline 97.0 & A.tr & $11 . r$ & THAT & A. $\leqslant \varepsilon$ & rel & $r \ldots$ \\
\hline$v \cdot .0$ & $9 . \varepsilon$ & $\vee . \wedge$ & rNTO & 1. 0. & צ & $r \ldots r$ \\
\hline or. $y$ & 9.10 & $0 . V$ & ronV & $1.0 \leqslant$ & $r \cdot r$ & $r \ldots r$ \\
\hline$\leq \wedge . \varepsilon$ & 9.4 & 0.1 & TIVT & 1. 7 . & ror & $r \ldots r$ \\
\hline$\varepsilon r .0$ & 9.17 & $\varepsilon . V$ & משוץ & 1.10 & $r \leqslant 1$ & $r \ldots \varepsilon$ \\
\hline rq.1 & 9.47 & $\varepsilon . r$ & $1 \wedge 11$ & 9.11 & 191 & r... \\
\hline ס. & Q. . . & 7.9 & $109 \varepsilon$ & 9.11 & 1vo & $r \ldots r$ \\
\hline
\end{tabular}




\begin{tabular}{|c|c|c|c|c|c|c|}
\hline$\varepsilon r . \varepsilon$ & $9 . \leqslant T$ & $\varepsilon .7$ & $19 \leq 7$ & 9.11 & $Y I T$ & $r \ldots V$ \\
\hline$\varepsilon r . V$ & 9.0 & $\varepsilon .7$ & $10 \% 0$ & $9 . Y 7$ & iv. & $r \ldots \lambda$ \\
\hline$\Sigma 1$. & 9.11 & $\varepsilon .0$ & $19 \leqslant 1$ & Q.Y. & YII & $r \ldots q$ \\
\hline 77.10 & 1.09 & $\vee .91$ & YY.T.A. & ᄉ...V & TVY.YO & المتوسط \\
\hline
\end{tabular}

جدول ملحق (r): تقدير الكفاءة الاقتصـادية للغناصر بدوال إنتـاج محصول الفول البلدى بعينـة الاراسـة

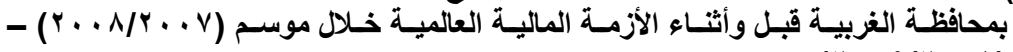

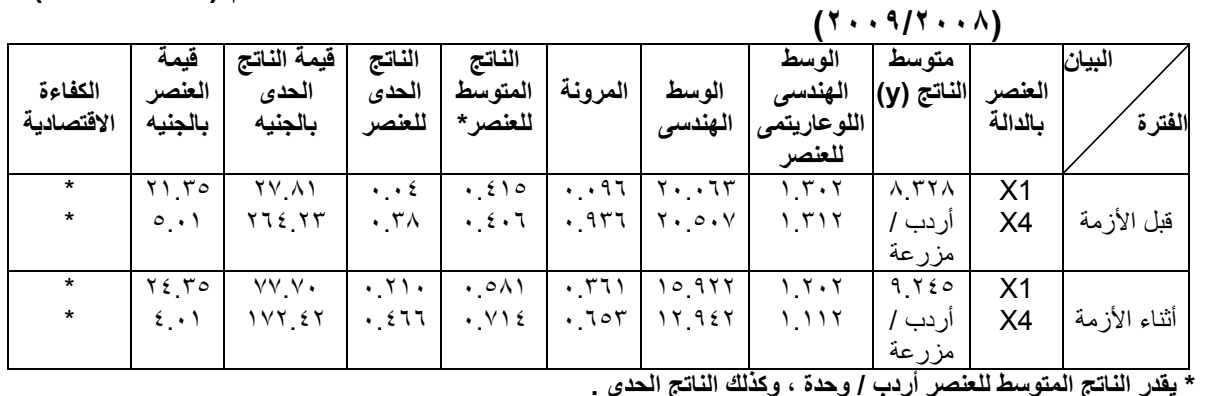

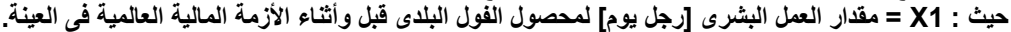

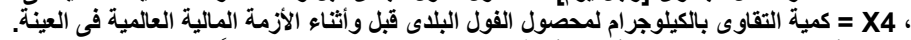

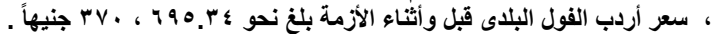

المصدر : جمعت وحسبث من بيانات الاستبيان الميدانى للعينة بمحافظة الغئ الغربية .

\section{AN ANALYTICAL STUDY FOR SOME ECONOMIC IMPACT OF THE GLOBAL FINANCIAL CRISIS ON THE PRODUCTION OF FABA BEAN CROP IN GHARBIA GOVERNORATE}

Easa, E. E.

Agricultural Economic Research Institute, Agric. Res. Center

\section{ABSTRACT}

The world is facing financial and economic crisis which is most of the food crisis that hit the world during the period from March 2007 until May 2008, that lead to decrease in growth rates of the global economy and lower world prices for major commodities and food products.

The problem with the study in the global financial crisis cast a shadow on world economies, including the Egyptian economy in general and the agricultural sector in particular, in addition to their impact on the economy of major cereal crops as beans. and foremost that, lower prices of farm and thus area planted with such crops as well as production and consumption and higher wages of agricultural workers.

The study aims to identify the implications of the financial crisis and economic crisis on the economies beans crop in Gharbia governorate of human and machine employment wage, and the price of raw materials, rent, production costs and product prices and yield and net return per feddan of these strategic crop.

The study also showed that the impact of the financial crisis had a positive 


\section{Easa, E. E.}

on: productivity of feddan of bean grain, and productive feddan of hay, and cultivated area with beans with rates increase were about $3.3 \%, 2.3 \%, 8 \%$ of the value of each of them before the crisis, respectively, and the impact of crisis negatively on all of the rent feddan of bean, the price of Alardb of beans, the price of beans carrying hay where the rates decreased were about $(26.6) \%,(46.8) \%,(69.2) \%$ of the value of all of them before the crisis in Gharbia governorate. The study also showed that the impact of the financial crisis was positive on each of the total variable costs, and the total cost of the farm labor of feddan of crop faba bean with rates increase reached to about $15.12 \%, 39.56 \%$ of the value of each of them before the financial crisis, respectively, while a negative impact on total cost requirements of beans per feddan with rates shortage reached about $(11.56) \%$ of the value of that cost before the financial crisis. The study also showed the impact of the financial crisis was negative on all the total costs, the total value of revenue, net revenue, and return investor pound of feddan of faba bean with ratios reached about $(0.34) \%,(47.6) \%,(93.8) \%,(92.9) \%$ of the value of each of them before the crisis, respectively. The study showed that the impact of financial crisis on the scale of optimization production of the farm was negative with proportions shortage reached about $(9.58) \%$ of the value of it before the crisis. The study also showed that the impact of financial crisis on the scale of profit maximization production of the profit of the farm was negative for faba bean with proportions shortage reached about $(6.87) \%$ of the value of profit maximization size of it before the crisis.

The study suggested some recommendation to increase the planted area of Faba bean by reducing the inputs price and increasing the from gate price of final product of this crop to encourage the farmer.

$$
\text { كلية الزراعة ـ جامعة المنصورة }
$$

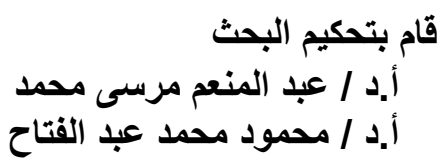

